\title{
Early Effects of Antiretroviral Therapy on Vitamin D Status and Some Nutritional Markers of HIV-1 Infected Patients: A Case Control Study in a Sub-Saharan Africa Setting
}

\author{
Claude Venessa Kapya Ouandji ${ }^{1}$, Vicky Jocelyne Ama Moor ${ }^{2,3}$, Jan René Nkeck ${ }^{2}$,Bertrand \\ Daryl Tcheutchoua Nzokou ${ }^{2 *}$, Laure Blanche Bidjoni ${ }^{3}$ \\ ${ }^{1}$ Health Sciences School of the Catholic University, Cameroon \\ ${ }^{2}$ Faculty of Medicine and Biomedical Sciences, University of Yaounde I, Cameroon \\ ${ }^{3}$ Biochemistry laboratory, University Teaching Hospital of Yaounde, Cameroon
}

*Corresponding Author: Bertrand Daryl Tcheutchoua Nzokou, Faculty of Medicine and Biomedical Sciences, University of Yaounde I, Cameroon

\begin{abstract}
:
Objective: To evaluate the early effect of antiretroviral therapy (ART) on vitamin D status and nutritional markers in HIV-1 infected patients.

Results: We compare the vitamin D status, and serum level of calcium, phosphorus and ferritin of 40 consenting HIV-1 positive patients at one month of ART with 40 ART-naïve HIV patients, as a control group. There was no statistical difference in vitamin D, phosphorus, calcium and ferritin concentrations between groups. Albuminemia was higher in patients on ART (36.1 [29.7-40.1]) compare to ART-naüve patients (33.7 [27.5-36.7]) ( $p<0.05)$.At one month of ART, we observed an increase in albuminemia, while vitamin D, phosphorus, calcemia and ferritinemia remain unchanged..
\end{abstract}

Keywords: Albuminemia, Antiretroviral Therapy, Calcemia, HIV-1, Phosphorus, Vitamin D

Abréviations: ART: Antiretroviral Therapy, HIV: Human Immunodeficiency Virus;

\section{INTRODUCTION}

By the end of the year 2018, United Nations for AIDS estimates that 37.9 million people were living with AIDS worldwide. Africa is the most affected continent with 25.8 million people infected, and around 540 thousand deaths out of the global 770,000deaths in 2018 [1]. HIV infection cause a drop in immunity, chronic inflammation and oxidative stress wichpredisposes to opportunistic infections such as tuberculosis, metabolic complications and carcinogenesis, thus worsening the prognosis of the disease [2,3].Two third of HIV patients livein LMIC (Low and Middle Income Countries) and face difficulties in accessing care. Also they suffer from undernourishment and malnutrition, and its resulting nutritional deficiencies [4].

Malnutrition in Africa accounts for about a quarter of the worldlwide prevalence. Climatic changes, conflicts and economic instability increase the burden of food insecurity and malnutrition in Africa [5]. HIV and malnutrition have bidirectional interactions; HIV contributes to malnutrition by reduced nutrient intake, malabsorption, increased energy expenditure and endocrine dysfunction [6,7]; On the other hand, malnutrition in HIV patients increases the risk for opportunistic infections, and reduces the effectiveness of antiretroviral treatment leading to a high mortality [7,8]. Malnutrition and undernourishment include various deficiencies such as vitamin D deficit, which prevalence varies between 18 and 46\% in Africa [9]. Vitamin D deficit is particularly harmful in HIV-infected patients because its plays an important role in innate and adaptive immune response, inflammation, oxidative stress and endothelial dysfunction [10,11]. It's deficiency in HIV infected patients will worsen the already decreased lymphocyte count, increasing morbimortality [11].

Antiretroviral therapy (ART)reduces viral replication, increase CD4 counts and progressively restores the immune and nutritional status. However, few data have reported its effects on vitamin D status in 
the early months of treatment. We conducted this study to assess the effects of ART on nutritional and vitamin D status in people suffering infected with HIV-1 after the first month of treatment.

\section{MATERIAL AND MeTHODS}

\subsection{Study Framework}

We conducted cross sectional study from January to April 2019 in the HIV unit of the Yaoundé Central Hospital.

\subsection{Participants}

Participants were 80 consenting HIV-1 positive patients aged 18 years and above. They were equally divided into two groups: Group 1 made up of 40 patients receiving ART (Tenofovir/ Lamivudine/ Efavirenz) at the first month of treatment, and a good adherence to treatment; Group 2 made up of 40 patients newly diagnosed on ART-naïve. The sample size was estimated using Cochran (1965:75) formula with $80 \%$ power and $5 \%$ error. The sampling was consecutive and non-exhaustive.

\subsection{Ethical Considerations}

The study was approved by the Institutional Ethics Committee of the Health Sciences School of the Catholic University

\subsection{Data Collection}

For each participant, we reported the age, gender and biological analysis were performed using $10 \mathrm{~mL}$ of peripheral venous blood sample to assess serum concentrations of calcium, albumin, phosphorus, ferritin and vitamin D. Albumin, calcium and phosphorus were determine using colorimetric techniques. Ferritin and vitamin D were determined using the competitive-ELISA technique. Calcemia was corrected with albumin.

\subsection{Operational Terms}

Vitamin D deficiency was defined less than $20 \mathrm{ng} / \mathrm{mL}$. It was severe, moderate and mild respectively less than $5 \mathrm{ng} / \mathrm{mL}$, between 5 and $9 \mathrm{ng} / \mathrm{mL}$ and between 10 and $19 \mathrm{ng} / \mathrm{mL}$. Normal vitamin D level could be low (between 20 and $29 \mathrm{ng} / \mathrm{mL}$ ), or high (above $30 \mathrm{ng} / \mathrm{mL}$ ). Hypoalbuminemia was defined for a value less than $34 \mathrm{~g} / \mathrm{L}$; Hypocalcemia was defined for a corrected calcemia less than $80 \mathrm{mg} / \mathrm{L}$. Hypoferritinemia was considered $<30 \mathrm{ng} / \mathrm{mL}$ and $<10 \mathrm{ng} / \mathrm{mL}$ respectively for men and women. Phosphorus levels was considered low for a value less than $26 \mathrm{mg} / \mathrm{L}$ (hypophosphatemia).

\subsection{Statistical Analysis}

Data were analyzed using the software SPSS version 22.0. The data were reported in median and interquartile range $\left(25^{\text {th }}\right.$ and $75^{\text {th }}$ quartiles) for quantitative variables and in effectives with proportions for categorical variables. We used the Fisher's exact test to compare proportions, and Median test for median comparison. The threshold of significance was set at 0.05 .

\section{RESUlTS AND DisCuSSION}

\subsection{Results}

Two third of the sample were female with no statistical difference between groups $(\mathrm{p} \geq 0.05)$. The median age was 43 [34-49]years for group 1 participants, but the difference was not statistically significant with group 2.

Vitamin D level comparison revealed no statistically significance difference between both groups $(\mathrm{p} \geq 0.05)$. Majority of the participants from both groups (40\% and $37.5 \%)$ had a mild deficiency in vitamin D level. However, repartition of vitamin D status was quite similar in both groups. Hypophosphatemia was observed in $15 \%$, and hypocalcemia in $50 \%$ of ART naïve patients. However, there was no difference in phosphorus and calcium metabolism in both groups

Regarding ferritin, serum concentration ofparticipants in group 1 was lower $(11.8[8.6-13.1] \mathrm{ng} / \mathrm{ml})$ compared to group 2 patients $(13.2[9.6-13.8] \mathrm{ng} / \mathrm{ml})$ with no statistical difference $(\mathrm{p} \geq 0.05)$.

Concerning nutritional status, albuminemia was higher in patients from group 1 (36.1 [29.7-40.1]) than in ART naïve patients (33.7 [27.5-36.7]) $(\mathrm{p}<0.05)$. The prevalence of hypoalbuminemia was lower in group 1(35\%) than group $2(52 \%)$. All the data are summarized in Table I. 
Early Effects of Antiretroviral Therapy on Vitamin D Status and Some Nutritional Markers of HIV-1 Infected Patients: A Case Control Study in a Sub-Saharan Africa Setting

Table1. Clinical and biological characteristics of the study sample

\begin{tabular}{|l|l|l|l|}
\hline \multicolumn{1}{|c|}{ Variables } & \multicolumn{1}{c|}{ Group 1 $(\mathbf{n = 4 0})$} & \multicolumn{1}{c|}{ Group 2 $(\mathbf{n = 4 0})$} & \multicolumn{1}{c|}{ p value } \\
\hline Age, years & $43,5[34-49]$ & $42.5[33.3-46.8]$ & $\geq 0.05$ \\
\hline Female, $\mathrm{n}(\%)$ & $31(77.5)$ & $26(65.0)$ & $\geq 0.05$ \\
\hline Vitamin D (ng/mL) & $21.21[12.68-32.72]$ & $21.10[16.33-35.52]$ & $\geq 0.05$ \\
\hline Moderate deficiency; $(\%)$ & $3(7.5)$ & $2(5.0)$ & \\
\hline Mild insufficiency; $\mathrm{n}(\%)$ & $16(40.0)$ & $15(37.5)$ & \\
\hline Normal low; $\mathrm{n}(\%)$ & $10(25)$ & $9(22.5)$ & \\
\hline Normal high; $\mathrm{n}(\%)$ & $11(27.5)$ & $14(35)$ & $\geq 0.05$ \\
\hline Calcemia, $(\mathrm{mg} / \mathrm{L})$ & $83[78.74-90.95]$ & $86.24[76.25-100.75]$ & \\
\hline Hypocalcemia; $\mathrm{n}(\%)$ & $24(60)$ & $20(50)$ & $\geq 0.05$ \\
\hline Ferritinemia $(\mathrm{ng} / \mathrm{mL})$ & $11.80[8.62-13.17]$ & $13,20[9.65-13.80]$ & \\
\hline Hypoferritinemia; $\mathrm{n}(\%)$ & $21(52.5)$ & $24(60.0)$ & $<\mathbf{0 5}$ \\
\hline Albuminemia $(\mathrm{g} / \mathrm{L})$ & $36.15[29.77-40.10]$ & $33.75[27.50-36.72]$ & \\
\hline Hypoalbuminemia $\mathrm{n}(\%)$ & $14(35)$ & $21(52.5)$ & $\geq 0.05$ \\
\hline Phosphoremia $(\mathrm{mg} / \mathrm{L})$ & $37.15[29.02-44.82]$ & $36.50[28.75-40.30]$ & \\
\hline Hypophosphoremia, $\mathrm{n}(\%)$ & $7(17.5)$ & $6(15.0)$ & \\
\hline
\end{tabular}

\subsection{Discussion}

HIV is still a major public health problem especially in Africa. It is closely associated to various nutritional deficiencies which are hoped to be restored with ART. We conducted a cross sectional study to compare the vitamin D status and nutritional markers of HIV-1 patients on ARTwith ART naïve patients. It appears that albumin concentrations are higher in ART group, but all the other parameters were similar in both groups. Albuminemia is a marker of nutritional status and is correlated with HIV infection progression and mortality [12]. In this study, serum albumin concentration is higher in ART patients, which suggests a better nutritional status compared to naive ART patients. These results corroborate those found by Michael Carter where, in HIV patients, an average serum albumin level of $32 \mathrm{mg} / \mathrm{L}$ was found before the beginning of anti-HIV treatment and this increased significantly to $37.7 \mathrm{mg} / \mathrm{L}(\mathrm{p}=0.004)$ after treatment [13].Similar results was also found in a cohort study in Uganda with an improvement of the nutritional status after 3 years of ART [14]. HIV infection is associated with inadequate nutrient intake with anorexia, malabsorption and psychosocialissues[15,16]. Also, there is an increase in global metabolism in uncontrolled HIV infection, opportunistic infections and cytokines dysregulation which contributes to a poor nutritional status [17]. Therefore, antiretroviral therapy will reduce viral load and improve nutritional status in HIV patients.

Vitamin D has wide-ranging effects on the immune system and low serum levels are associated with worse clinical outcome. Its levels were similar in our study between ART patients and ART naïve patients. These results contrast some recent studies that suggest that antiretrovirals, particularly Efavirenz are associated with low serum concentrations. Carolien et al in 2008 in Netherland found that non-nucleoside reverse transcriptase inhibitor (NNRTI) were associated with vitamin D deficiency [18]. Nylen et al found in an Ethiopian cohort that Efavirenz based therapy is associated with high incidence of severe vitamin D deficiency [19]. These data suggest that ART in particular Efavirenz may leads to low levels of vitamin D. This effect of the Efavirenz is hypothesized to occur through the induction of 24-hydroxylase, a cytochrome $\mathrm{P} 450$ enzyme, that inactivates $25 \mathrm{OH}$ vitamin $\mathrm{D}$ and $1,25 \mathrm{OH}$ vitamin $\mathrm{D}[20]$. Our findings, which differ from those found in the literature, can be explained by the duration of ART use. Indeed, in our study, the patients had been under treatment for less than 3 months. The results of Fiona et al. support this hypothesis because they found a sharp drop of serum concentration of vitamin $\mathrm{D}$ in the 6 first months after ART initiation, with a much slower decline or a stagnation between 24 and 48 weeks of treatment[21]. The effect of Efavirenz on vitamin D levels would therefore be more pronounced at the initiation of treatment and less pronounced over the long term.

The short duration of ART may also explain no difference in calcemia, phosphorus and ferritinemia in both groups which differs from the results of Noe et al, where they found an association between Tenofovir and high risk of hypocalcemia[22]. Hypocalcemia in ART patients can be explain by the effect of some antiretroviral therapies such as Tenofovir of Efavirenz on vitamin D metabolism, leading to low vitamin D concentration and therefore low calcemia[20,23]. Apart from ART duration, our population age was higher than those of the authors cited above. Contreras-Manzano et al found an increase in iron deficiency with age which is explained by reduce absorption and storage capacity due to age [24]. 


\section{CONCLUSiON}

Our results suggest that early effects of ART at one month, on nutritional status is marked by an increase in albuminemia, while vitamin $\mathrm{D}$, phosphorus, calcemia and ferritinemia globally remain unchanged. A follow up of this population will give further results.

\section{ACKNOWLEDGEMENT}

Dr Charles KOUANFACK who help for the recruitment of the patients; Dr Agoons BATAKEH Ba who help for the translation of the manuscript.

\section{REFERENCES}

[1] Global HIV \& AIDS statistics — 2019 fact sheet [Internet]. [cité 25 mars 2020]. Disponible sur: https:// www.unaids.org/en/resources/fact-sheet

[2] Currier JS, Havlir DV. CROI 2019: Complications and Coinfections in HIV Infection. Top Antivir Med. 1 avr 2019;27(1):34-40.

[3] Danforth K, Granich R, Wiedeman D, Baxi S, Padian N. Global Mortality and Morbidity of HIV/AIDS. In: Holmes KK, Bertozzi S, Bloom BR, Jha P, éditeurs. Major Infectious Diseases [Internet]. 3rd éd. Washington (DC): The International Bank for Reconstruction and Development / The World Bank; 2017 [cité 25 mars 2020]. Disponible sur: http://www.ncbi.nlm.nih.gov/books/NBK525184/

[4] Frank TD, Carter A, Jahagirdar D, Biehl MH, Douwes-Schultz D, Larson SL, et al. Global, regional, and national incidence, prevalence, and mortality of HIV, 1980-2017, and forecasts to 2030, for 195 countries and territories: a systematic analysis for the Global Burden of Diseases, Injuries, and Risk Factors Study 2017. Lancet HIV. 1 déc 2019;6(12):e831-59.

[5] Lastname F. Chapter 2: Global, Regional, and National Trends [Internet]. woop.ie. [cité 25 mars 2020]. Disponible sur: http://www.woop.ie/url/

[6] Zemede Z, Tariku B, Kote M, Estifanos W. Undernutrition and associated factors among HIV-positive adult patients enrolled in antiretroviral therapy (ART) clinics in the Arba Minch area, southern Ethiopia. HIVAIDS Auckl NZ. 1 juill 2019;11:147-54.

[7] Ivers LC, Cullen KA, Freedberg KA, Block S, Coates J, Webb P. HIV/AIDS, Undernutrition and Food Insecurity. Clin Infect Dis Off Publ Infect Dis Soc Am. 1 oct 2009;49(7):1096-102.

[8] Duggal S, Chugh TD, Duggal AK. HIV and Malnutrition: Effects on Immune System [Internet]. Clinical and Developmental Immunology. 2012 [cité 25 mars 2020]. Disponible sur: https://www.hindawi.com/journals/jir/ 2012/784740/

[9] Mogire RM, Mutua A, Kimita W, Kamau A, Bejon P, Pettifor JM, et al. Prevalence of vitamin D deficiency in Africa: a systematic review and meta-analysis. Lancet Glob Health. 1 janv 2020;8(1):e134-42.

[10] JE L, JS A. Vitamin D in HIV-Infected Patients. Curr HIV/AIDS Rep. sept 2011;8(3):133-41.

[11] Alvarez N, Aguilar-Jimenez W, Rugeles MT. The Potential Protective Role of Vitamin D Supplementation on HIV-1 Infection. Front Immunol [Internet]. 2019 [cité 25 mars 2020];10. Disponible sur: https://www. frontiersin.org/articles/10.3389/fimmu.2019.02291/full

[12] Drain PK, Baeten JM, Overbaugh J, Wener MH, Bankson DD, Lavreys L, et al. Low serum albumin and the acute phase response predict low serum selenium in HIV-1 infected women. BMC Infect Dis. 19 mai 2006;6(1):85.

[13] Albumin levels can predict HIV disease severity and indicate success of antiretroviral therapy [Internet]. aidsmap.com. [cité 26 mars 2020]. Disponible sur: https://www.aidsmap.com/news/sep-2006/albuminlevels-can-predict-hiv-disease-severity-and-indicate-success-antiretroviral

[14] Weiser SD, Gupta R, Tsai AC, Frongillo EA, Grede N, Kumbakumba E, et al. Changes in food insecurity, nutritional status, and physical health status after antiretroviral therapy initiation in rural Uganda. J Acquir Immune Defic Syndr 1999. 1 oct 2012;61(2):179-86.

[15] Mangili A, Murman DH, Zampini AM, Wanke CA, Mayer KH. Nutrition and HIV Infection: Review of Weight Loss and Wasting in the Era of Highly Active Antiretroviral Therapy from the Nutrition for Healthy Living Cohort. Clin Infect Dis. 15 mars 2006;42(6):836-42.

[16] Woods MN, Spiegelman D, Knox TA, Forrester JE, Connors JL, Skinner SC, et al. Nutrient intake and body weight in a large HIV cohort that includes women and minorities. J Am Diet Assoc. févr 2002;102(2):203-11.

[17] Mwamburi DM, Wilson IB, Jacobson DL, Spiegelman D, Gorbach SL, Knox TA, et al. Understanding the role of HIV load in determining weight change in the era of highly active antiretroviral therapy. Clin Infect Dis Off Publ Infect Dis Soc Am. 1 janv 2005;40(1):167-73. 
[18] Van Den Bout-Van Den Beukel CJP, Fievez L, Michels M, Sweep FCGJ, Hermus ARMM, Bosch MEW, et al. Vitamin D Deficiency among HIV Type 1-Infected Individuals in the Netherlands: Effects of Antiretroviral Therapy. AIDS Res Hum Retroviruses. 18 oct 2008;24(11):1375-82.

[19] Nylén H, Habtewold A, Makonnen E, Yimer G, Bertilsson L, Burhenne J, et al. Prevalence and risk factors for efavirenz-based antiretroviral treatment-associated severe vitamin D deficiency: A prospective cohort study. Medicine (Baltimore). août 2016;95(34):e4631.

[20] Yin M, Stein E. The Effect of Antiretrovirals on Vitamin D. Clin Infect Dis. 1 févr 2011;52(3):406-8.

[21] Havers FP, Detrick B, Cardoso SW, Berendes S, Lama JR, Sugandhavesa P, et al. Change in Vitamin D Levels Occurs Early after Antiretroviral Therapy Initiation and Depends on Treatment Regimen in Resource-Limited Settings. PLOS ONE. 21 avr 2014;9(4):e95164.

[22] Noe S, Heldwein S, Jaeger H, Page M, Wolf E. Tenofovir disoproxil fumarate/emtricitabine is associated with a higher risk of hypocalcemia compared to abacavir/lamivudine - results from a German cohort study. Int J STD AIDS. 1 avr 2019;30(5):447-52.

[23] Klassen K, Martineau AR, Wilkinson RJ, Cooke G, Courtney AP, Hickson M. The effect of tenofovir on vitamin D metabolism in HIV-infected adults is dependent on sex and ethnicity. PloS One. 2012; 7(9):e44845.

[24] Contreras-Manzano A, Cruz V de la, Villalpando S, Rebollar R, Shamah-Levy T. Anemia and iron deficiency in Mexican elderly population: Results from the Ensanut 2012. Salud Publica Mex. oct 2015;57(5):394-402.

Citation: Claude Venessa Kapya Ouandji et.al., (2020). "Early Effects of Antiretroviral Therapy on Vitamin D Status and Some Nutritional Markers of HIV-1 Infected Patients: A Case Control Study in a SubSaharan Africa Setting”, International Journal of Clinical Chemistry and Laboratory Medicine (IJCCLM), 6(1), pp.12-16. DOI: http://dx.doi.org/10.20431/2455-7153.0601003

Copyright: (c) 2020 Authors, This is an open-access article distributed under the terms of the Creative Commons Attribution License, which permits unrestricted use, distribution, and reproduction in any medium, provided the original author and source are credited. 